\title{
Aberrant Cytoplasmic Accumulation of Connexin 43 in Human Testicular Seminoma
}

\author{
V. Mauro ${ }^{1}$, D. Chevallier ${ }^{2}$, J. Gilleron ${ }^{1}$, N. Defamie ${ }^{3}$, D. Carette ${ }^{1}$, J.M. Gasc ${ }^{4}$, F. Senegas-Balas ${ }^{1}$, \\ D. Segretain ${ }^{1}$ and G. Pointis*,1
}

\begin{abstract}
${ }^{I}$ INSERM U 895, Team 5 «Physiopathologic control of germ cell proliferation: genomic and non genomic mechanisms», 151 route Saint-Antoine de Ginestière, BP 2 3194, 06204 Nice cedex 3, France and Université Paris Descartes, 45 rue des Saint-Pères, 75006, Paris, France; ${ }^{2}$ Department of Urology, Pasteur Hospital, Nice, France; ${ }^{3}$ Institut de Physiologie et Biologie Cellulaire, UMR-CNRS 6187, Université de Poitiers, France and ${ }^{4}$ INSERM U833, Collège de France, Paris, France
\end{abstract}

\begin{abstract}
In the present study Cx43 mRNA and protein were analyzed in germ cells of men with normal spermatogenesis and in human testicular seminoma. In normal testis Cx43 mRNAs were basally located within seminiferous tubules and expressed in the most basally located germ cells (spermatogonia, early spermatocytes, and pachytene spermatocytes) and in Sertoli cells. Immunofluorescence analysis showed that $\mathrm{Cx} 43$ signal was mainly located in the basal compartment of seminiferous tubules and was stage-dependent. Cx43 mRNAs were also detected in human testicular seminoma. Transcripts were present within seminoma cells identified by PLAP staining. However, Cx43 protein exhibited an intracytoplasmic accumulation, within an intracellular compartment distinct from the Golgi apparatus and was undetectable at the plasma membrane level, suggesting post-translational rather than transcriptional abnormalities. This aberrant intracytoplasmic accumulation of $\mathrm{Cx} 43$ is due neither to a dysfunction of the protein trafficking machinery nor to a specific alteration of its major protein partner, $\mathrm{ZO}-1$, since the tight junction associated protein was detected at the plasma membrane level and did not colocalize with $\mathrm{Cx} 43$.
\end{abstract}

\section{INTRODUCTION}

Gap junctions are clusters of plasma membrane channels, formed of proteins called connexin $(\mathrm{Cx})$, which allow the intercellular exchange of small signaling molecules $(<1 \mathrm{kD})$ between the cytoplasmic compartments of two adjacent cells [1]. Gap junctional intercellular communication (GJIC) is involved in the regulation of cellular growth, tissue differentiation, homeostasis and neoplasic transformation [2].

There is now strong evidence that mutated $\mathrm{Cx}$ genes could result in human genetic disorders [3]. Specifically, impaired GJIC and Cx dysfunction have been described as a typical feature of cancer per se and have been associated with the actions of carcinogens. Indeed, altered GJIC has been shown to correlate with neoplastic transformation in several human tissues [4]. In many cancer cases this alteration has been associated with aberrant intracytoplasmic localization of $\mathrm{Cx}$ proteins $[5,6]$.

In the rodent testis, the presence of gap junctions was morphologically shown and these results were supported by the identification of mRNAs for at least eleven Cxs [7]. Targeted disruption of $\mathrm{Cx} 43$ gene, the predominant $\mathrm{Cx}$ in the testis, resulted in a deficiency of germ cell development and initiation of spermatogenesis indicating that $\mathrm{Cx} 43$ play a major role in the developing process of germ cells [8-12]. Whether a similar role of $\mathrm{Cx} 43$ could be exerted in human

*Address correspondence to this author at the Bâtiment Universitaire ARCHIMED, INSERM U 895, C3M, 151 route Saint Antoine de Ginestière, BP 2 3194, 06204 Nice cedex 3, France; Tel: (33) 04890642 66; Fax: (33) 04890642 66; E-mail: pointis@unice.fr was also hypothesized. Gap junctions were described in infertile azoospermic and oligospermic human testes [13] but were undetectable in patients with Sertoli-cell-only seminiferous tubules [14]. In addition, $\mathrm{Cx}^{4} 43$ protein was localized in both tubular and interstitial compartments of human testis [15] and affected Cx43 levels were found in testis with Sertoli-cell-only syndrome [16-18].

In human testis infiltrated with carcinoma-in-situ or seminoma, $\mathrm{Cx} 43$ was undetectable by immunohistochemical approaches [19] and reduced Cx43 mRNA levels were measured in neoplastic human testis [20,21]. In a previous study using neoplastic cells originating from the JKT1 seminoma cell line we reported that overexpression of $\mathrm{Cx} 43$ by transfection of a Cx43-GFP vector not only restores GJIC but also blocks abnormal proliferation of these cells [22]. These observations raised the question of the role of endogenous $\mathrm{Cx} 43$ in these tumoral cells.

In the present study, we first identified by in situ hybridization (ISH) and indirect immunofluorescence the specific cells that express $\mathrm{Cx} 43$ within the seminiferous tubules of human testis. Second we compared the Cx43 levels between healthy and seminoma human testes. Lastly, to better address the role of $\mathrm{Cx} 43$ in the testicular tumoral process we analyzed Cx43 mRNA expression and Cx43 localization in human testis seminoma.

\section{MATERIALS AND METHODOLOGY}

\section{Human Tissue Collection and Cell Line}

Biopsies of normal testes were performed in young men (28-38 years) with excretory azoospermia due to deferent 
duct agenesis, after informed and written consent, according to INSERM Ethical Guideline $(n=8)$ and approval by the local ethic committee. Three frozen testicular tumors were classified as pure seminoma by placental like alkaline phosphatase (PLAP) positive staining, a specific seminoma marker [23]. The JKT1 cell line that originated from a pure human testicular seminoma [24] was maintained in DMEM supplemented with 10\% FBS (Gibco Brl, Cergy Pontoise, France) as previously reported [22].

\section{In Situ Hybridization (ISH)}

Briefly, the radiolabelled Cx43 antisense and Cx43 sense probes were generated by in vitro transcription and incorporation of ${ }^{35} \mathrm{~S}$-uridine triphosphate (specific ratio activity, $1000 \mathrm{Ci} / \mathrm{mmol}$, Amersham, UK) as previously described [25]. Testicular sections $(5 \mu \mathrm{m})$ received the antisense RNA probe and the other received the RNA sense probe as background control. After washing, the slides were dipped in NTB2 emulsion (Kodak, Rochester, NY) and exposed at $4^{\circ} \mathrm{C}$ in lightness boxes for 15 days. Slides were developed, fixed, and counterstained with toluidine blue. Hybridization intensity was quantified using a computer-assisted image analysis system Visilog 4.15 (Noesis, Les Ulis, France) as reported [25]. The intensity of hybridization was expressed as percentage of pixels within a marked area occupied by silver grains that was above a set grey threshold level. Measurements were taken from 10 seminiferous tubules from 3 different sections for each testis. Data were expressed as means \pm SEM. A one way analysis of variance ANOVA followed by a Student-Newman-Keuls post hoc test was used to test for differences between cell types. Values were considered statistically different when $\mathrm{p}<0.05$.

\section{Immunofluorescence analysis}

The integrity of spermatogenesis was tested by fixing a piece of each testis in aqueous Bouin, which was examined by classical histological procedures. Stages identification of the seminiferous epithelium were identified according to morphological criteria, including the depth and shape of elongate spermatid nuclei in Sertoli cells, the presence or absence of two generations of spermatids (round and elongate spermatids), and the size of the acrosome surmounting the round spermatid nucleus according to criteria previously described [26].

For immunofluorescence analyses, tissues were embedded in OCT embedding compound (Tissue Tek; Miles Inc., Naperville, ILL) and cryosectioned. Sections $(7 \mu \mathrm{m})$ were then applied to 3-aminopropyltriethoxysilane-coated slides and fixed for $10 \mathrm{~min}$ with methyl alcohol at $-20^{\circ} \mathrm{C}$ and treated as described above. Testis sections were incubated for $2 \mathrm{~h}$ with the rabbit anti-Cx43 antibody (1:100 Zymed Laboratories, San Francisco, CA) and mouse-anti-vimentin (Sigma-Aldrich, St. Quentin-Fallavier, France) and subsequently incubated with goat anti-rabbit FITC conjugated and goat anti-mouse TRITC conjugated antibodies (Jackson Immunoresearch Laboratories, Baltimore, U.K.). For studies on the JKT1 cell line, cells were fixed in cold methyl alcohol at $-20^{\circ} \mathrm{C}$ for $5 \mathrm{~min}$, washed with PBS and incubated with mouse anti-Cx43 and rabbit anti-ZO-1 antibodies (1:50, Zymed Laboratories) in PBS containing 3\% BSA, $1 \%$ normal goat serum (Dako, Glostrup, Denmark), overnight at $4^{\circ} \mathrm{C}$ as previously reported [25]. Cells were rinsed with PBS and then incubated for $1 \mathrm{~h}$ with an Alexa fluor 488 conjugated goat anti-rabbit F(ab') ${ }_{2}$ IgG (1:50, Molecular Probe, Eugene, OR) and a rhodamine $\mathrm{Red}^{\mathrm{TM}}-\mathrm{X}$-labelled $\mathrm{F}(\mathrm{ab})_{2}$ fragment of goat anti-mouse antibody (1:50, Jackson ImmunoResearch, West Grove, PA) in PBS containing 3\% BSA, $1 \%$ normal goat serum. After washing with PBS, the slides were mounted in Vectashield medium supplemented by DAPI (Vector Laboratories, Burlingame, CA). For detection of the Golgi apparatus, tissue sections and cells were concomitantly incubated with $\mathrm{Cx} 43$ antibody and with a specific Golgi apparatus CTR433 antibody (1/10, a gift from M. Bornens, Institut Curie, Paris France). Slides were then examined with a confocal laser scanning microscope (Leica TCS SP).

High-resolution deconvolution microscopy analysis was performed with a wide field immunofluorescence deconvolution microscope (Nikon TE2000E, Service Commun de Microscopie, IFR Biomédicale des Saint-Pères, Paris, France) and acquired image stacks were deconvoluted using Autoquant image package algorithms as previously described [27].

For PLAP immunolocalization, tissue sections or cells were incubated with a monoclonal mouse anti-PLAP antibody (clone 8A9) purchased from Dako (1/100, Giostrup, Denmark). Slides were subsequently incubated with a Horseradish peroxidase-labelled $\mathrm{F}\left(\mathrm{ab}^{\prime}\right) 2$ fragment of anti-mouse IgG (1:500) for $2 \mathrm{~h}$. Staining was completed by incubation with 3, 3'diaminobenzidine. Slides were counterstained with hemalun and washed in tap water. Controls were performed by incubating slides with whole pre-immune mouse serum (1:100, Jackson ImmunoResearch, West Grove, PA), instead of the primary antisera, or PBS replacing the conjugated antibody.

\section{RESULTS}

\section{Analysis of Cx43 mRNA and Protein in Human Normal Germ Cells}

In situ hybridization analysis of $\mathrm{Cx} 43$ was carried out on testicular biopsies of patients with excretory azoospermia. Histological analyses of these testes revealed normal spermatogenesis (data not shown). Darkfield images demonstrate a high accumulation of silver grains at the base of seminiferous tubules and in the interstitial compartment of human testis with normal spermatogenesis. In addition, the pattern of Cx43 mRNA distribution appeared variable within and between seminiferous tubules (Fig. 1A). Control sections incubated with the sense probe revealed a low non specific hybridization signal (Fig. 1B). The human seminiferous epithelium cycle is divided into six stages and at least three spermatogenic stages can be observed in the same seminiferous tubule sections [26]. Three spermatogenic stages have been analyzed here. At stage I, characterized by the presence of two generations of spermatids and pachytene spermatocytes a consistent ISH signal for $\mathrm{Cx} 43$ was detected in the basal compartment (Fig. 1C). The number of silver grains was markedly reduced at stage II identified by the elongated spermatids moving to the luminal aspect of the seminiferous epithelium (Fig. 1D). The seminiferous tubules corresponding to stage $\mathrm{V}$, where one generation of elongating spermatids having typically pointed and deeply stained nuclei directed toward the limiting membrane, appeared also strongly 

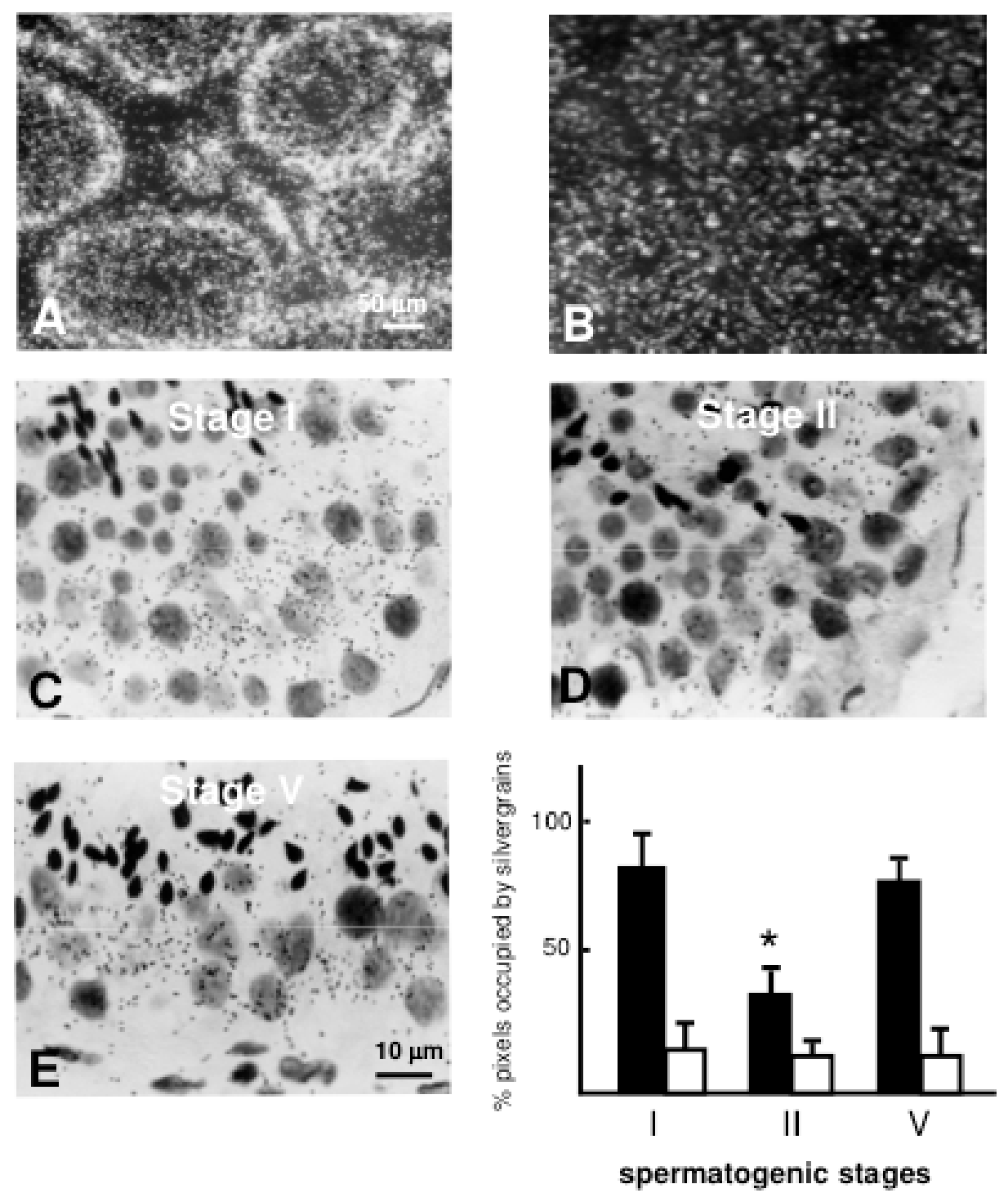

Fig. (1). Stage-dependence localization of Cx43 mRNA in seminiferous tubules of human testis. Darkfield micrographs of seminiferous tubules section hybridized with ${ }^{35}$ S-labelled antisense (A) and sense (B) Cx43 RNA probes. A and B have the same magnification. High magnification of brightfield micrographs illustrates the variation of intensity of Cx43 mRNA distribution among seminiferous tubules. The hybridization signal is consistent at stages I and V of spermatogenesis $(\mathbf{C}$ and $\mathbf{E})$ and relatively reduced at stage II (D). Cx43 mRNA are present mostly in the cytoplasms of Sertoli cells and in basally located germ cells. C-E have the same magnification. The lower right panel represents semi-quantitative analysis of the Cx43 ISH signals in seminiferous epithelium of human normal testis at stage I, II and V. Representative of three different experiments. The intensity of hybridization was quantified as percentage pixels occupied by silver grains. Black columns represent analysis of antisense hybridization. Open columns represent analysis of sense hybridization. Values are means \pm SEM, $\mathrm{n}=20$. $\mathrm{P}<0.05$ as compared to stages I and $\mathrm{V}$.

labelled (Fig. 1E). Semi-quantitative analysis indicated that the intensity of the signal, measured with the antisense probe, was significantly lower $(\mathrm{P}<0.05)$ at stage II compared to stages I and V.

High magnifications of the basal ISH signal revealed that silver grains were localized over and/or surrounded the nuclei of spermatogonia (Fig. 2A), early spermatocytes (Fig. 2B) and pachytene spermatocytes (Fig. 2C). A slight ISH signal similar to that observed in control sections incubated with the sense probe (data not shown) was detected in round and elongated spermatids. Semi-quantitative analysis of Cx43 mRNA indicated that the levels of silver grains in spermatogonia and in pachytene spermatocytes were not significantly different from those quantified in the Sertoli cells (right lower panel) suggesting that gap junction communication occurs between the somatic cells and germ cells.

The existence of $\mathrm{Cx} 43$ based gap junctions between Sertoli cells and germ cells was verified by the presence of $\mathrm{Cx} 43$ immunosignals between a vimentin-positive cell, identified as Sertoli cells, and a vimentin-negative cell corresponding to spermatogonia as suggested by their small cytoplasmic surfaces, the shape of their nuclei and their basal localization within the seminiferous tubule (Fig. 3A), and between vimentin-positive Sertoli cells (Fig. 3B). 

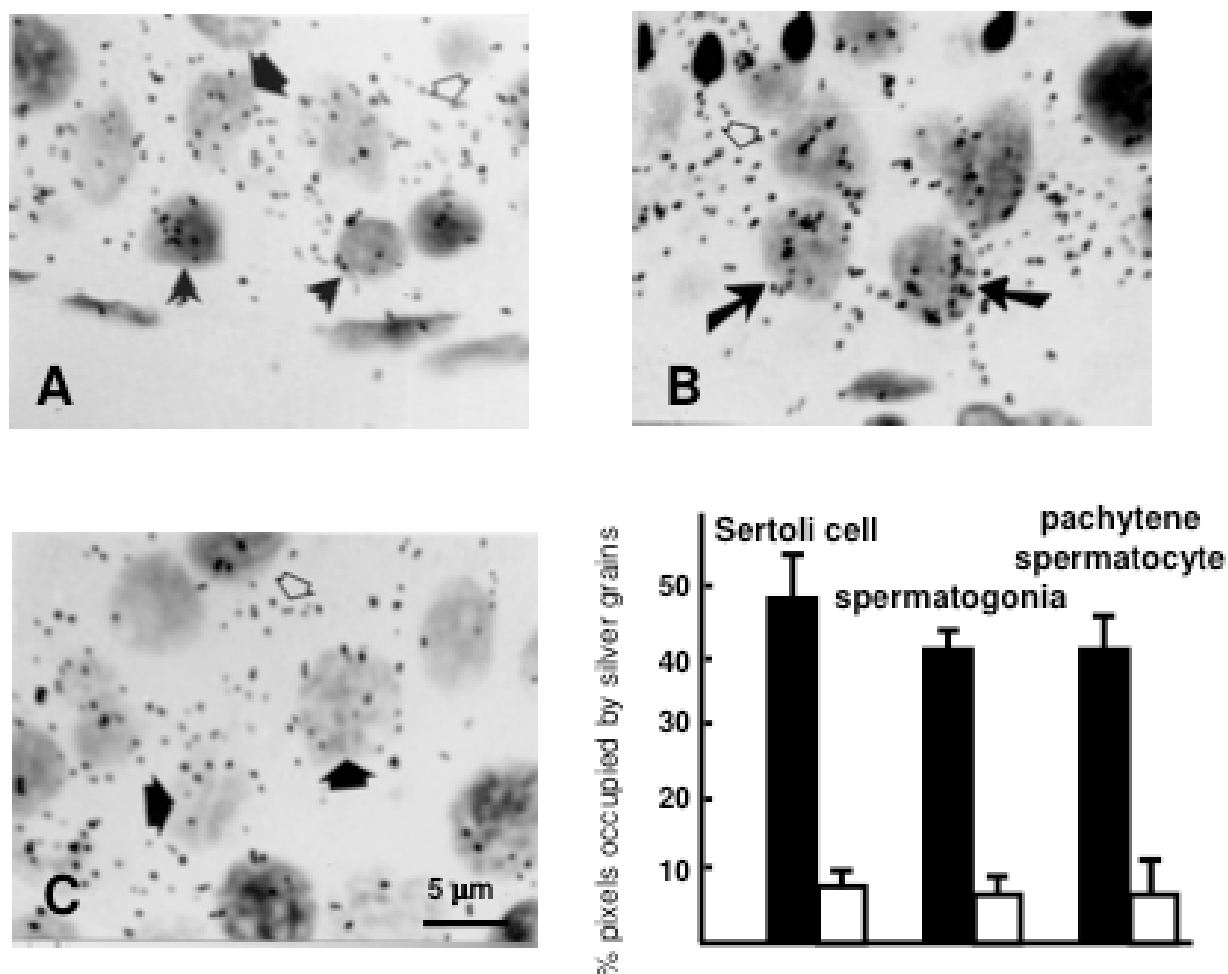

Fig. (2). Localization of $\mathrm{Cx} 43 \mathrm{mRNA}$ in seminiferous tubules of human testis. High magnification of the basally located ISH signal shows that silver grains are associated with spermatogonia (A, arrowheads), early spermatocytes (B, small arrows) and pachytene spermatocytes $(\mathbf{C}$, large arrows). ISH signal was also detected over the intercellular germ cell spaces which represent the Sertoli cell cytoplasm (open arrows in A, B and C). A-C have the same magnification. Representative of three different experiments. The lower right panel represents semiquantitative analysis of Cx43 ISH signal in seminiferous epithelium of human normal testis. The intensity of hybridization in Sertoli cells, spermatogonia and pachytene spermatocytes was quantified as percentage pixels occupied by silver grains. Black columns represent analysis of antisense hybridization. Open columns represent analysis of sense hybridization. Values are means \pm SEM, $n=30$.
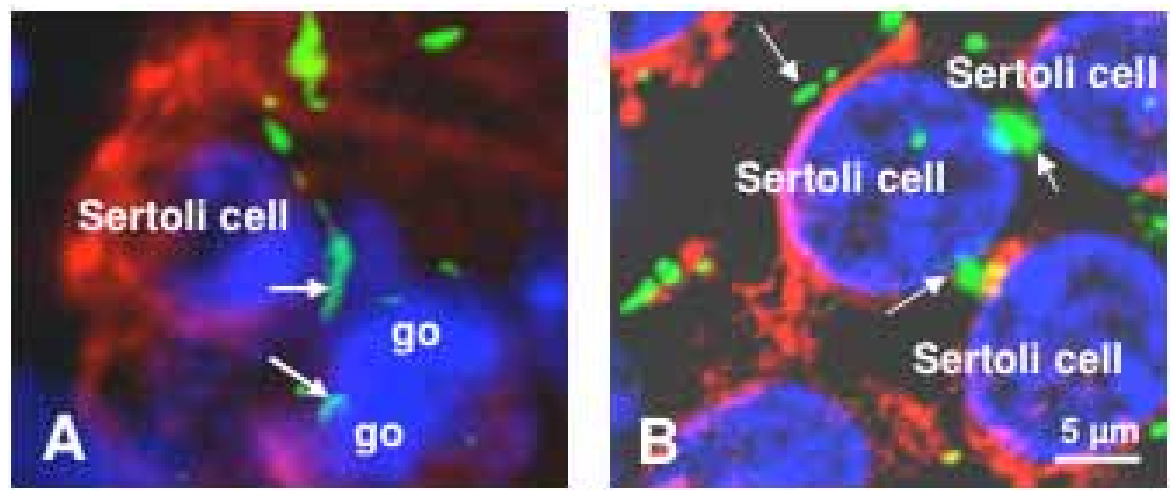

Fig. (3). Immunolocalization of $\mathrm{Cx} 43$ within the seminiferous epithelium of human testis. (A) Localization of Cx43 (green fluorescence, arrows) between a vimentin-positive cell identified as a Sertoli cell (red fluorescence) and spermatogonia (go) identified by the shape of their nuclei and their localization within the seminiferous tubule. Cell nuclei are identified by Dapi staining. (B) Localization of Cx43 (green fluorescence, arrows) between vimentin-positive Sertoli cells (red fluorescence). Representative of three different experiments. A and $\mathbf{B}$ have the same magnification.

\section{Analysis of Cx43 mRNA and Protein in Human Testicu- lar Seminoma}

Cx43 mRNAs were detected in the three human testicular seminoma analyzed. As shown in Fig. 4A, darkfield micrographs of human seminoma hybridized with labelled antisense probe revealed a high accumulation of silver grains that were distributed on all the surface of the seminoma section. High magnifications of brightfield micrographs showed that Cx43 mRNAs were mainly located in the cytoplasms of seminoma cells (Fig. 4B, arrows). No IHS signal was detected in lymphocytes (double arrowhead) or in red blood cells present in the tumor. Control sections incubated with the sense probe revealed a slight unspecific signal (Fig. 4B, inset).

As expected seminoma cells were PLAP-positive (Fig. 4C). Immunofluorescence analysis revealed strong Cx43 

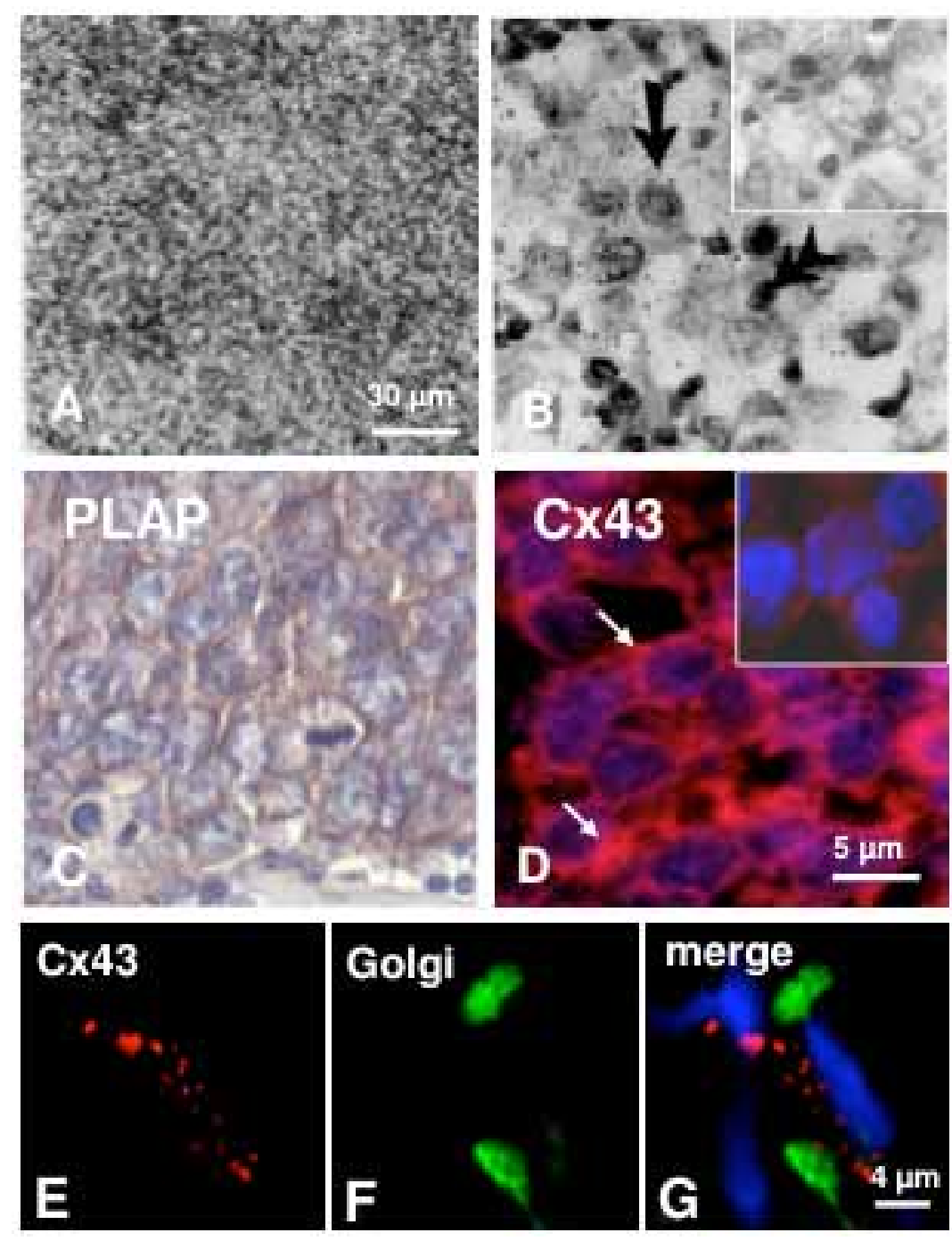

Fig. (4). Cx43 mRNA and Cx43 protein in pure human testicular seminoma. (A) Darkfield micrographs of human seminoma hybridized with ${ }^{35}$ S-labelled antisense Cx43 mRNA probe. (B) High magnification of brightfield micrographs shows that silver grains were mainly located in the cytoplasm of seminoma cells (arrow) whereas they were absent in lymphocytes (double arrowhead). Control sections incubated with the sense probe revealed a slight but unspecific signal (inset). (C) All seminoma cells appear PLAP-positive. A signal for Cx43 protein was detected in the majority of seminoma cells with perinuclear localization (D, arrows). No specific Cx43 specific staining was detected in control cells (D, inset). (E-G) Immunodetection of Cx43 (red fluorescence) and of Golgi apparatus (green fluorescence) by high-resolution deconvolution microscopy. Cell nuclei are identified by Dapi staining. Representative of three different experiments. B-D and E-G have the same magnification respectively.

signals within the cytoplasms of these cells (Fig. 4D) and their total absence at the cell-cell contacts as classically described in normal communicating cells. No distinct $\mathrm{Cx} 43$ immunoreactive signal was detected in control cells (Fig. 4D, inset). The Cx43-antibody mainly labelled a perinuclear region that might be identified as Golgi-like structures (Fig. 4D). To verify this hypothesis high-resolution deconvolution microscopy was applied on the same testicular sections immunolabelled with $\mathrm{Cx} 43$ and a specific marker of the Golgi apparatus (Figs. 4E-G). In no cases, $\mathrm{Cx} 43$ colocalized with the Golgi apparatus. As observed in testicular tumoral tissues, seminoma JKT1 (Fig. 5A) that expressed PLAP (Fig. $\mathbf{5 A}$, inset) exhibited a perinuclear intracytoplasmic localization of $\mathrm{Cx} 43$ (Figs. 5C,D,G). This localization contrast with the Cx43 membranous level observed in the 42GPA9 Sertoli cell line used as a control (Fig. 5D, inset). Application of high-resolution deconvolution microscopy demonstrated that this intracytoplasmic $\mathrm{Cx} 43$ labeling in most cases did not colocalized with the specific Golgi apparatus marker (Figs. 5E,F). Dual immunofluorescence analysis with antibodies directed against $\mathrm{Cx} 43$ and ZO-1 also demonstrated that the two proteins did not colocalize within the same cellular compartment (Figs. 5G-I). In contrast to $\mathrm{Cx} 43$, ZO-1 was never detected within the cytoplasm of JKT1 cells but appeared localized as small dots at the zone of contact between adjacent cells (Fig. 5H).

\section{DISCUSSION}

Although there is compelling evidence that $\mathrm{Cx} 43$ gap junctions occurred, between Sertoli cells, the presence of Cx43 between the somatic cells and germ cells are less evidenced. The current in situ hybridization study clearly demonstrates that $\mathrm{Cx} 43$ transcripts are present in both Sertoli cells and basally located germ cells: spermatogonia, early 

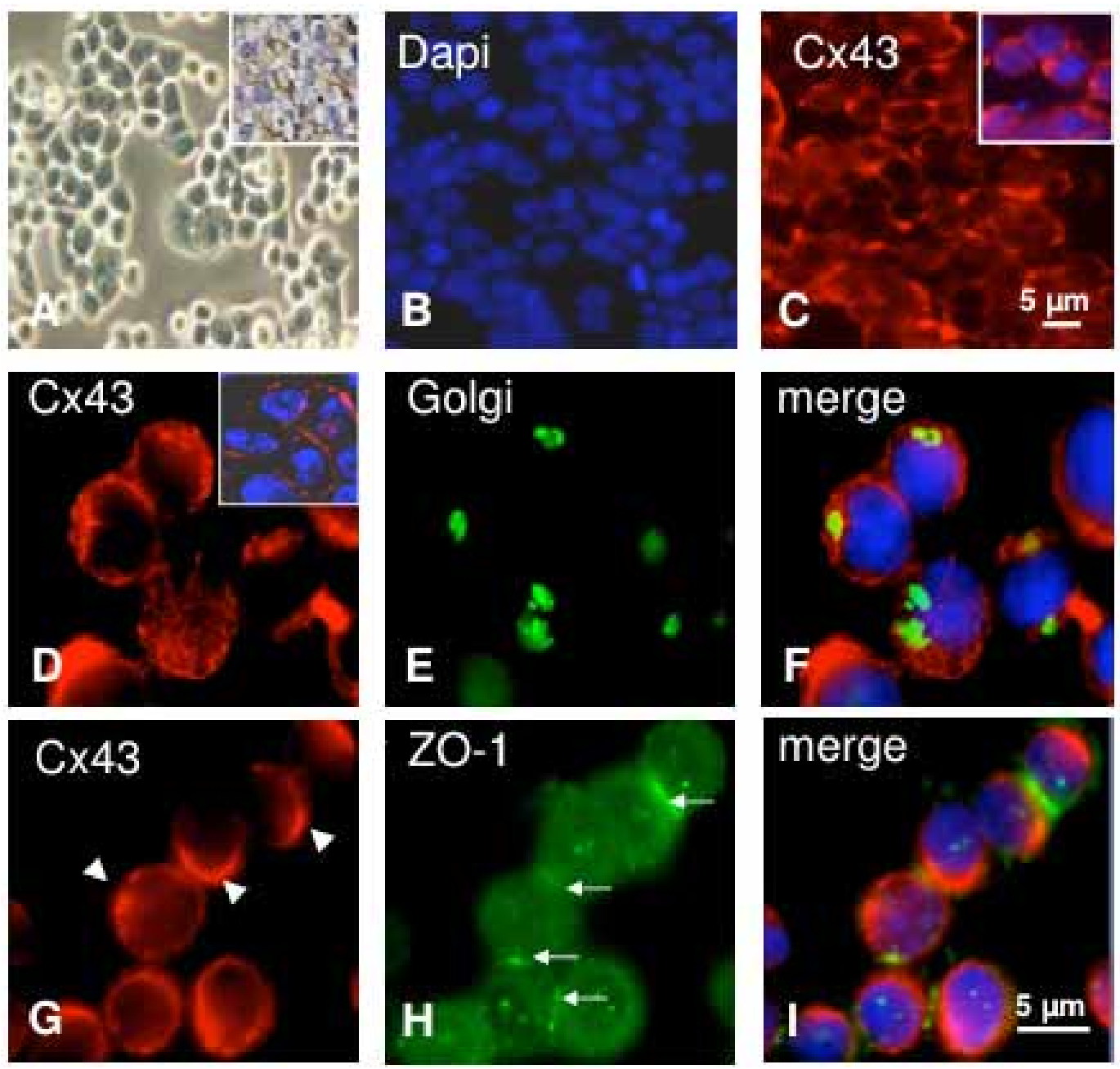

Fig. (5). Immunolocalization of PLAP, Cx43 and ZO-1 in the JKT1 cell line. (A) Phase contrast microscopy of cultured JKT1 cells and analysis of the expression of PLAP (inset). (C) Immunodetection of Cx43 in JKT1 cells. Cell nuclei are identified by Dapi staining (B) and inset in $\mathrm{C}$ reveals both labeling. (D-F) and (G-I) Dual immunofluorescence of Cx43 (red fluorescence in $\mathbf{D}$ and $\mathbf{G}$ ) and the Golgi apparatus (green fluorescence in $\mathbf{E}$ ) or ZO-1 (green fluorescence in $\mathbf{H}$ ) in JKT1 cells analyzed by high-resolution deconvolution microscopy. The inset in D represents a positive control for Cx43 membranous localization observed in a Sertoli cell line. Note that Cx43 does not colocalize either with the Golgi apparatus or with ZO-1 (F and I). Representative of three different experiments. D-I have the same magnification.

spermatocytes and pachytene spermatocytes supporting recent findings [21]. In addition the present observation that Cx43 transcripts are equally distributed in the somatic and germinal cells leads to the assumption that channels formed by $\mathrm{Cx} 43$ occur between these two cell types. These data do not preclude that other Cxs, detected within the seminiferous epithelium as $\mathrm{Cx} 26$ and $\mathrm{Cx} 32$ that are able to form channels by them or in association with the two other Cxs, participate in this gap junctional cell-to-cell communication [28]. This hypothesis is, however, not in agreement with previous observations in rodents, which show that $\mathrm{Cx} 43$ protein is mainly found in the basal compartment whereas Cx26 and Cx32 are specifically detected in the apical compartment of the seminiferous epithelium [29]. From altogether these data and in agreement with our findings that $\mathrm{Cx} 43$ is closed to gap junction channels [30] it is likely that gap junctions, which occur basally between Sertoli and germ cells, are mainly formed by $\mathrm{Cx} 43$.

Cx43 gene expression was down-regulated in human testis infiltrated with carcinoma-in-situ or in testicular semi- noma [19-21]. For the latter authors the proliferation of neoplasic germ cells in the tumoral testis could result from a loss of Sertoli cell control on germ cells due to altered Sertoli cell Cx43 expression. However, no information was given on Cx43 expression in neoplasic germ cells. The current data, in seminoma testis section and in the JKT1 seminoma cell line, demonstrate that the main characteristic of seminoma cells is an aberrant accumulation of the $\mathrm{Cx} 43$ protein within the cytoplasm rather than a reduced $\mathrm{Cx} 43$ expression since ISH and immunohistochemical analyses demonstrate the maintenance of high levels of Cx43 mRNA and protein in the pathological tissue. This does not preclude that altered $\mathrm{Cx} 43$ gene expression might occur later during the tumoral development. The present findings support our previous data [22] and are in agreement with observations reported in other human tumoral tissues, in which an aberrant localization of Cxs has been observed, such as human liver tumors [31], breast tumors [32], prostate cancers [33] and bladder cancers [34] and more recently in human hepatoma cells [35]. However the role that intracytoplasmic localized $\mathrm{Cx}$ could play is 
questionable. In addition to be involved in the classical gap junction communication, $\mathrm{Cx}$ proteins have been suggested to play additional roles when they are present within the cytoplasm [35, 36] or in the nucleus [37] mainly in tumoral tissues or tumoral cell lines. Thus it appeared interesting to specify the intracytoplasmic nature of $\mathrm{Cx} 43$ in seminoma tissue and cell line.

By using conventional imaging technology we previously reported in the JKT1 cell line that $\mathrm{Cx} 43$ accumulated in a cellular compartment identified as the Golgi apparatus [22]. Such localization has been also recently reported in hepatocellular carcinoma [35]. By using high-resolution deconvolution microscopy we demonstrated in the present work that Cx43 does not accumulated in the Golgi apparatus in seminoma tissue sections and in the JKT1 seminoma cell line. The precise localization of $\mathrm{Cx} 43$ remains to be determined. Since the Cx43 immunolabeling appears randomly distributed within all the cytoplasm, the possibility of impaired trafficking of $\mathrm{Cx} 43$ has been hypothesized. Altered global mechanisms implicated in the trafficking of proteins in the cytoplasm are unlikely since transfection of JKT1 cells with a tagged Cx43-GFP vector allows accumulation of the green fluorescent $\mathrm{Cx} 43$ protein to the plasma membrane level and concomitantly inhibit abnormal proliferation of these tumoral cells [22]. This hypothesis is also supported by the observation that the tight junction associated protein ZO-1 was detected at the plasma membrane level. Abnormality in Sertoli cell functions during testicular tumor progression has been suggested $[38,39]$. Thus it is possible that the aberrant Cx43 localization result from a loss of normal Sertoli cells as regulators of $\mathrm{Cx} 43$ trafficking and assembly at the plasma membrane of seminoma cells [21]. If it is the case, it would be interesting to characterize the paracrine effectors from the Sertoli cells, which could be able to control cytoplasmic Cx43 trafficking. Cxs are also capable of interacting with a large number of proteins that control not only their ability to form functional channels but also their turnover to the membrane, formation, stability and internalization of gap junction plaques [40]. Thus it may be hypothesized that one of these partners abnormally associates with $\mathrm{Cx} 43$ and sequesters the latter within the intracytoplasmic compartment. To date the nature of this protein is unknown. Among the large number of Cx partners characterized [41], Zonula Occludens 1 (ZO1) has been reported to be the major $\mathrm{Cx}$ interacting protein and an essential role of this protein in the turnover of gap junction formation and degradation has been postulated [4245]. The current data clearly show that $\mathrm{Cx} 43$ and ZO-1 did not colocalize suggesting that ZO-1 is not the partner of Cx43 responsible for this specific cytoplasmic accumulation. In contrast ZO-1 was mainly present at the plasma membrane level between adjacent cells confirming that the general process involved in the trafficking of membranous proteins to the membrane was probably not affected. Whether other interacting proteins could play this role remains to be investigated. There is also evidence that the phosphorylation status of the $\mathrm{Cx} 43 \mathrm{C}$-terminus could play a role in regulating Cx43 trafficking, assembly/disassembly and internalization and is under the control of various kinases [46]. Among them the Src tyrosine kinase that has been implicated in the progression of a wide variety of cancers, although no direct relationship between Src activation and testicular seminoma has been reported [47]. Thus it is possible that alteration of conformation of the $\mathrm{C}$ terminal region of $\mathrm{Cx} 43$ by specific phosphorylation sites controls its exit from the Golgi apparatus to the plasma membrane as recently suggested [48].

\section{CONCLUSION}

In conclusion the present results show that altered $\mathrm{Cx} 43$ gene expression in human testicular seminoma mainly occurs at the protein level suggesting post-translational rather than transcriptional abnormalities. They show that aberrant cytoplasmic accumulation of $\mathrm{Cx} 43$ probably associated with altered $\mathrm{Cx} 43$ trafficking to the plasma membrane is a typical feature of testis seminoma cells and is a potential process for uncontrolled germ cell proliferation in this cancer. Whether intracytoplasmic Cx per se can play favorable effects for tumor progression as suggested in other tumoral tissues [35] is presently questionable.

$\begin{array}{ll}\text { ABBREVIATIONS } \\ \mathrm{CX}=\text { Connexin } \\ \text { GJIC } & =\text { Gap junctional intercellular communication } \\ \text { PLAP } & =\text { Placental like alkaline phosphatase } \\ \text { ZO-1 } & =\text { Zonula Occludens } 1 \\ \text { GFP } & =\text { Green fluorescent protein } \\ \text { ISH } & =\text { In situ hybridization } \\ \text { AEC } & =\text { Amino ethyl carbazol }\end{array}$

\section{CONFLICT OF INTEREST}

This work was supported in part by the Institut National de la Santé et de la Recherche Médicale (INSERM) and by a grant Projet Hospitalier de Recherche Clinique (PHRC, contract $\mathrm{n}^{\circ}$ 04-APR-03).

\section{REFERENCES}

[1] Goodenough DA, Goliger JA, Paul DL. Connexins, connexons, and intercellular communication. Annu Rev Biochem 1996; 65: 475502 .

[2] Kumar NM, Gilula NB. The gap junction communication channel. Cell 1996; 84: 381-8.

[3] Willecke K, Eiberger J, Degen J, et al. Structural and functional diversity of connexin genes in the mouse and human genome. Biol Chem 2002; 383: 725-37.

[4] Trosko JE. The role of stem cells and gap junctional intercellular communication in carcinogenesis. J Biochem Mol Biol 2003; 36: 43-8.

[5] Mesnil M, Crespin S, Avanzo JL, Zaidan-Dagli ML. Defective gap junctional intercellular communication in the carcinogenic process. Biochim Biophys Acta 2005; 1719: 125-45.

[6] Pointis G, Fiorini C, Gilleron J, Carette D, Segretain D. Connexins as precocious markers and molecular targets for chemical and pharmacological agents in carcinogenesis. Curr Med Chem 2007; 14: 2288-303.

[7] Risley MS. Connexin gene expression in seminiferous tubules of the Sprague-Dawley rat. Biol Reprod 2000; 62: 748-54.

[8] Juneja SC, Barr KJ, Enders GC, Kidder GM. Defects in the germ line and gonads of mice lacking connexin43. Biol Reprod 1999; 60: 1263-70.

[9] Plum A, Hallas G, Magin T, et al. Unique and shared functions of different connexins in mice. Curr Biol 2000; 10: 1083-91.

[10] Roscoe WA, Barr KJ, Mhawi AA, Pomerantz DK, Kidder GM. Failure of spermatogenesis in mice lacking connexin43. Biol Reprod 2001; 65: 829-38.

[11] Brehm R, Zeiler M, Rüttinger C, et al. Sertoli cell-specific knockout of connexin43 prevents initiation of spermatogenesis. Am J Pathol 2007; 171: 19-31. 
[12] Sridharan S, Simon L, Meling DD, et al. Proliferation of adult sertoli cells following conditional knockout of the Gap junctional protein GJA1 (connexin 43) in mice. Biol Reprod 2007; 76: 80412.

[13] Bigliardi E, Vegni-Talluri M. Gap junctions between Sertoli cells in the infertile human testis. Fertil Steril 1977; 28: 755-8.

[14] Cavicchia JC, Sacerdote FL, Ortiz L. The human blood-testis barrier in impaired spermatogenesis. Ultrastruct Pathol 1996; 20: 211 8 .

[15] Steger K, Tetens F, Bergmann M. Expression of connexin 43 in human testis. Histochem Cell Biol 1999; 112: 215-20.

[16] Defamie N, Berthaut I, Mograbi B, et al. Impaired gap junction connexin43 in Sertoli cells of patients with secretory azoospermia: a marker of undifferentiated Sertoli cells. Lab Invest 2003; 83: 44956.

[17] Matsuo Y, Nomata K, Eguchi J, et al. Immunohistochemical analysis of connexin43 expression in infertile human testes. Acta Histochem Cytochem 2007; 40: 69-75.

[18] Kotula-Balak M, Hejmej A, Sadowska J, Bilinska B. Connexin 43 expression in human and mouse testes with impaired spermatogenesis. Eur J Histochem 2007; 51: 261-8.

[19] Brehm R, Marks A, Rey R, Kliesch S, Bergmann M, Steger K. Altered expression of connexins 26 and 43 in Sertoli cells in seminiferous tubules infiltrated with carcinoma-in-situ or seminoma. J Pathol 2002; 197: 647-53.

[20] Okada K, Katagiri T, Tsunoda T, et al. Analysis of gene-expression profiles in testicular seminomas using a genome-wide cDNA microarray. Int J Oncol 2003; 23: 1615-35.

[21] Brehm R, Rüttinger C, Fischer P, et al. Transition from preinvasive carcinoma in situ to seminoma is accompanied by a reduction of connexin 43 expression in Sertoli cells and germ cells. Neoplasia 2006; 8: 499-509.

[22] Roger C, Mograbi B, Chevallier D, et al. Disrupted traffic of connexin 43 in human testicular seminoma cells: overexpression of Cx43 induces membrane location and cell proliferation decrease. $\mathrm{J}$ Pathol 2004; 202: 241-6.

[23] Lange PH, Millan JL, Stigbrand T, Vessella RL, Ruoslahti E, Fishman WH. Placental alkaline phosphatase as a tumor marker for seminoma. Cancer Res 1982; 42: 3244-7.

[24] Kinugawa K, Hyodo F, Matsuki T, et al. Establishment and characterization of a new human testicular seminoma cell line, JKT-1. Int J Urol 1998; 5: 282-7.

[25] Batias C, Siffroi JP, Fenichel P, Pointis G, Segretain D. Connexin43 gene expression and regulation in the rodent seminiferous epithelium. J Histochem Cytochem 2000; 48: 793-05.

[26] Clermont Y. The cycle of the seminiferous epithelium in man. Am J Anat 1963; 112: 35-51.

[27] Segretain D, Decrouy X, Dompierre J, et al. Sequestration of connexin43 in the early endosomes: an early event of Leydig cell tumor progression. Mol Carcinog 2003; 38: 179-87.

[28] Bruzzone R, White TW, Paul DL. Connections with connexins: the molecular basis of direct intercellular signaling. Eur $\mathrm{J}$ Biochem 1996; 238: 1-27.

[29] Risley MS, Tan IP, Roy C, Saez JC. Cell-, age- and stagedependent distribution of connexin43 gap junctions in testes. J Cell Sci 1992; 103: 81-96.

[30] Decrouy X, Gasc JM, Pointis G, Segretain D. Functional characterization of $\mathrm{Cx} 43$ based gap junctions during spermatogenesis. J Cell Physiol 2004; 200: 146-54.
[31] Krutovskikh V, Mazzoleni G, Mironov N, et al. Altered homologous and heterologous gap-junctional intercellular communication in primary human liver tumors associated with aberrant protein localization but not gene mutation of connexin32. Int J Cancer 1994; 56: 87-94.

[32] Jamieson S, Going JJ, D'Arcy R, George WD. Expression of gap junction proteins connexin 26 and connexin 43 in normal human breast and in breast tumors. J Pathol 1998; 184: 37-43.

[33] Mehta PP, Perez-Stable C, Nadji M, Mian M, Asotra K, Roos BA. Suppression of human prostate cancer cell growth by forced expression of connexin genes. Dev Genet 1999; 24: 91-110.

[34] Gee J, Tanaka M, Grossman HB. Connexin 26 is abnormally expressed in bladder cancer. J Urol 2003; 169: 1135-7.

[35] Li Q, Omori Y, Nishikawa Y, Yoshioka T, Yamamoto Y, Enomoto K. Cytoplasmic accumulation of connexin 32 protein enhances motility and metastatic ability of human hepatoma cells in vitro and in vivo. Int J Cancer 2007; 121: 536-46.

[36] Omori Y, Li Q, Nishikawa Y, et al. Pathological significance of intracytoplasmic connexin proteins: implication in tumor progression. J Membr Biol 2007; 218: 73-7.

[37] Mennecier G, Derangeon M, Coronas V, Hervé JC, Mesnil M. Aberrant expression and localization of connexin43 and connexin30 in a rat glioma cell line. Mol Carcinog 2008; 47: 391-401.

[38] Skakkebaek NE, Rajpert-De Meyts E, Jorgensen N, et al. Germ cell cancer and disorders of spermatogenesis: an environmental connection? APMIS 1998; 106: 3-11.

[39] de Kretser D. Testicular cancer and infertility. BMJ 2000; 321: 781-2.

[40] Giepmans BN. Gap junctions and connexin-interacting proteins. Cardiovasc Res 2004; 62: 233-45.

[41] Hervé JC, Derangeon M, Bahbouhi B, Mesnil M, Sarrouilhe D. The connexin turnover, an important modulating factor of the level of cell-to-cell junctional communication: comparison with other integral membrane proteins. J Membr Biol 2007; 217: 21-33.

[42] Toyofuku T, Yabuki M, Otsu K, Kuzuya T, Hori M, Tada M. Direct association of the gap junction protein connexin-43 with ZO-1 in cardiac myocytes. J Biol Chem 1998; 273: 12725-31.

[43] Barker RJ, Price RL, Gourdie RG. Increased association of ZO-1 with connexin43 during remodeling of cardiac gap junctions. Circ Res 2002; 90: 317-24.

[44] Seki A, Duffy HS, Coombs W, Spray DC, Taffet SM, Delmar M Modifications in the biophysical properties of connexin 43 channels by a peptide of the cytoplasmic loop region. Circ Res 2004; 95: 228 .

[45] Segretain D, Fiorini C, Decrouy X, Defamie N, Prat JR, Pointis G. A proposed role for $\mathrm{ZO}-1$ in targeting connexin 43 gap junctions to the endocytic pathway. Biochimie 2004; 86: 241-4.

[46] Solan JL, Lampe PD. Connexin phosphorylation as a regulatory event linked to gap junction channel assembly Biochim Biophys Acta 2005; 1711: 154-63.

[47] Frame MC. Src in cancer: deregulation and consequences for cell behaviour. Biochim Biophys Acta 2002; 1602: 114-30.

[48] Sosinsky GE, Solan JL, Gaietta GM, et al. The C-terminus of connexin43 adopts different conformations in the Golgi and gap junction as detected with structure-specific antibodies. Biochem J 2007; 408: $375-85$

(C) Mauro et al.; Licensee Bentham Open.

This is an open access article licensed under the terms of the Creative Commons Attribution Non-Commercial License (http://creativecommons.org/licenses/by-nc/3.0/) which permits unrestricted, non-commercial use, distribution and reproduction in any medium, provided the work is properly cited. 